\title{
Extraction of lignin from wastes of sugarcane bagasse and its utilization as an admixture for Portland cement
}

\author{
H.H.M. Darweesh ${ }^{a,}{ }^{*}$
}

${ }^{a}$ Refractories, Ceramics and Building Materials Department, National Research Centre, Cairo, Egypt

*Corresponding author Email: hassandarweesh2000@yahoo.com

DOI: https://doi.org/10.34256/nnxt2113

Received: 26-03-2021; Accepted: 29-03-2021; Published: 30-03-2021

Abstract: The influence of the prepared carboxy-methylated lignin extracted from sugarcane bagasse was investigated. Results showed that the $\mathrm{w} / \mathrm{c}$ ratio and also setting times of the blank (LO) were reduced with the lignin content. The heat of hydration, combined water content, bulk density and compressive strength of the blank (LO) slightly increased with increasing of lignin content, but only up to $0.3 \%$ lignin (L5) and then decreased. The free lime content decreased with the lignin content nearly at all hydration times up to 90 days due to the gradual reduction of the cement portion. The total porosity of the blank (LO) reduced gradually with lignin content up to $0.3 \%$ lignin, and then increased with further increase of lignin. The FTIR spectra illustrated that the rate of hydration increased with lignin content. The SEM-EDAX image analysis showed the improved microstructure of cement pastes in presence of carboxy-methylated lignin when compared with that of the blank.

Keywords: Cement, Lignin, Setting, Density, Porosity, Strength, FTIR, SEM-EDAX.

\section{High lights}

1. The $w / c$ ratio as well as setting times decreased with the addition of lignin.

2. The heat of hydration, combined water and free lime contents, bulk density and compressive strength slightly increased with the incorporation of lignin in the cement mixes.

3. The lignin admixture acts as a plasticizer and also as a retarder.

4. The FTIR spectra showed that the lignin improves the hydration process of the cement phases.

5. The SEM-EDAX image analysis demonstrated that small ratios of ettringite and portlandite as well as larger ratios of CSH in presence of lignin when compared with the blank.

\section{Introduction}

\subsection{Scope of the problem}

It is well known that the prices of the conventional Portland cement clinker are continuously increasing worldwide due to the over population. This had been led us to look for another alternative local materials suitable to use in the construction process in order to obtain low price buildings. Sugarcane bagasse (SCB) is a solid waste material created after the extraction of sugar juice from sugarcane. Generally, the bagasse waste is disposed to the landfills or disposal sites so that it now represents a heavy environmental load. Moreover, the SCB creates an environmental nuisance due to the direct disposal on the open areas so that it can form garbage heaps in these areas [1-7]. Barroso et al, 2003 [8] stated that one ton from sugarcane could generate $280 \mathrm{~kg}$ of bagasse waste. There are huge quantities of sugar are produced worldwide. Therefore, the solid waste of bagasse coming from sugar industry is nearly about $40-45 \%$. Hence, the annual discard of bagasse is about 600 million tons. To reduce the environmental burden of this $\mathrm{SCB}$, the utilization of this waste material in cement pastes, mortars or even concrete is a significant aspect $[3-5,7,8]$.

In bio-refineries, lignin which is the second largest component of biomass, is always separated from the cellulose, which in turn it is converted to ethanol. Most of the plant residues are waste biomass

On this basis, sugarcane bagasse residues are one of these biomasses. When lignin and cellulose could be separated from this waste using a low pressure and ecofriendly method, the lignin might be then able to be converted to a sustainable bio-product, which it successfully could be used in cement as an admixture $[9,10]$. The deep eutectic solvents are considered to be 
deconstructing waste biomasses having the potential to be technically and economically a viable alternative to volatile organic solvents [10-15].

Lignin is a three-dimensional, highly crosslinked macromolecule composed of three types of substituted phenols, which include: coniferyl, sinapyl, and p-coumaryl alcohols by enzymatic polymerization, yielding a vast number of functional groups and linkages (Figure. 1). There is a wide range of lignin sources available, including: jute, hemp, cotton, and wood pulp. Hence, the lignin's physical and chemical behavior will be different with respect to the original source and extraction method used. Lignin is the second most abundant natural polymer $[16,17]$. Lignin is insoluble in water and stable in nature and acts as the "glue" that connects cellulose and hemi-cellulose [18]. The areas in which lignin is applicable include: emulsifiers, dyes, synthetic floorings, sequestering, binding, thermosets, dispersal agents, paints and fuels to treatments for roadways [19].

There is a wide range of cellulose and lignin sources available including: jute, hemp, cotton and wood pulp. Hence, their physical and chemical behavior will be different with respect to the original source and extraction method used. Therefore, their use in many applications may vary based on formulations. For instance, lignosulfonates, with respect to the sulfite pulping process is one of the traditional forms of lignin that has been used for the high sulfonic acid functional groups which gives them great binding and emulsifying properties.

Sulfonated lignin separated from cellulose using the Kraft process could be utilized as a plasticizer in cement. Using the deep eutectic solvents, lignin from the waste biomass, which is sulfur-free, could be able to serve as a cement plasticizer to reduce the water/cement ratio needed for suitable workability. This is mainly due to that a lower water/cement ratio could improve and increase the mechanical properties of the hardened cement pastes [20]. Wheat straw lignin had to be carboxy-methylated to improve its ability to disperse graphite suspensions [18-20]. So, the lignin extracted from the sugarcane bagasse must be carboxymethylated and hence, its plasticizing effect becomes to be better when compared to those extracted from other plant residues.

\subsection{Objectives of the study}

The prepared carboxy-methylated lignin, extracted from sugarcane bagasse, was applied in Portland cement as a mineral admixture to study its effect of the physical, chemical, mechanical and microstructure properties of Portland cement pastes. The obtained results were then confirmed by Fourier transform infrared spectroscopy (FTIR) and Scanning electron microscop (SEM) supported with EDAX analysis.

\section{Experimental}

\subsection{Materials}

The raw materials used in this research study are Ordinary Portland cement (OPC Type I- CEM I $42,5 R$ ) with a blaine surface area $3400 \mathrm{~cm}^{2} / \mathrm{g}$ and sugarcane bagasse (SCB), Various chemicals used for the extraction of lignin like choline chloride powder (CCP) as a bio-reagent suitable for cell culture, $\geq 98 \%$ ), formic acid (FA), a reagent grade of $\geq 95 \%$, monochloro-acetic acid (MCAA) and sodium hydroxide $(\mathrm{SH})$, hydrogen peroxide $(\mathrm{HP})$ and distilled water of Sigma-Aldrich Inc., USA were purchased from ElGomhoria Company for Chemicals, Ramsis street, Egypt.. The OPC sample was supplied from Sakkara cement factory, Giza, Egypt, and its commercial name is known as "Asmant El-Momtaz". The chemical analysis of the OPC samples as conducted by X-ray fluorescence technique (XRF) is shown in Table 1 , while the mineralogical composition of the OPC is shown in Table 2.

\subsection{Extraction of lignin}

The lignin could be extracted by two methods:

\subsubsection{The first method}

Formic acid (FA) and choline chloride powder (CC) were first mixed in a molar ratio $2: 1$, respectively to make a deep eutectic solvent (DES) on a water bath at $60^{\circ} \mathrm{C}$ for 30 minutes with a continuous stirring till the mixture tends to be clear. Then, it was dried at $105^{\circ} \mathrm{C}$ for a day, and sieved sugarcane bagasse as biomass was mixed with $300 \mathrm{~g}$ DES in a conical flask comprising a condenser at its top to condense and return back any of the vaporized solvent. Then, it was immersed in an oil bath at about $152{ }^{\circ} \mathrm{C} \pm 2{ }^{\circ} \mathrm{C}$ for two hours. It was vacuum filtrated to separate the solid content. 
Table 1 Composisition of the used raw materials, mass \%.

\begin{tabular}{|l|l|l|l|l|l|l|l|l|l|l|}
\hline Oxides Materials & $\mathrm{Fe}_{2} \mathrm{O}_{3}$ & $\mathrm{Al}_{2} \mathrm{O}_{3}$ & $\mathrm{Fe}_{2} \mathrm{O}_{3}$ & $\mathrm{CaO}$ & $\mathrm{MgO}$ & $\mathrm{SO}_{3}$ & $\mathrm{Na}_{2} \mathrm{O}$ & $\mathrm{K}_{2} \mathrm{O}$ & LOI & Specific gravity \\
\hline OPC & 21.78 & 4.13 & 3.15 & 61.11 & 2.16 & 2.78 & 0.11 & 0.65 & 0.87 & 3.14 \\
\hline SCB & 70.83 & 9.21 & 1.95 & 8.16 & 1.32 & 1.47 & 0.12 & 1.65 & 6.91 & 2.23 \\
\hline
\end{tabular}

Table 2 Mineralogical composition of the used OPC sample, mass $\%$.

\begin{tabular}{|l|l|l|l|l|}
\hline Phases Material & $\mathbf{C}_{3} \mathbf{S}$ & $\boldsymbol{\beta}-\mathbf{C}_{2} \mathbf{S}$ & $\mathbf{C}_{3} \mathbf{A}$ & $\mathbf{C}_{4} \mathbf{A F}$ \\
\hline OPC & $\mathbf{4 3 . 0 1}$ & $\mathbf{3 0 . 0 0}$ & $\mathbf{5 . 6 5}$ & $\mathbf{9 . 5 8}$ \\
\hline
\end{tabular}

Figure 1. Lignin<smiles>COc1cc(/C=C/C=O)cc(Oc2ccc(C(O)C(CO)Oc3ccc(C(O)C(=O)CO)cc3OC)cc2Oc2cc(C(O)C(=O)COc3ccc(C(O)C(=O)CO)cc3)ccc2O)c1</smiles>

Figure 2 Chemical structure of lignin.<smiles>COc1cc(C=CCO)ccc1O</smiles>

coniferyl alcohol<smiles>COc1cc(C=CCO)cc(OC)c1O</smiles>

sinapyl alcohol<smiles>OCC=Cc1ccc(O)cc1</smiles>

p-coumaryl alcohol

Figure 3 Structural units of lignin. 
About, $28 \mathrm{ml}$ ethyl alcohol was added to the remaining solids with stirring for 9 minutes, prior to refiltration. Almost $1750 \mathrm{ml}$ water was added to the ligninalcohol mixture at room temperature for 24 hours. In the following day, a precipitate at the bottom of the conical flask was noted which is known as lignin. This was vacuum filtered to get rid of the DES-water-ethanol filtrate, and to obtain lignin alone (Figure. 1). The precipitated lignin was then dried in a vacuum oven for 24 hours at $60^{\circ} \mathrm{C}$ [21]. The extraction ratio was around $1 / 6$ for each biomass/lignin, i.e. one gram of lignin (LG) was extracted from 6 grams of biomass. The chemical structure of lignin is shown in Figure. 2, while its separate units are illustrated in Figure. 3.

\subsubsection{The second method}

Lignin extraction from sugarcane bagasse biomass started by pulping, i.e. the biomass was cut into small pieces, and then placed in a conical flask. A mixture of formic acid (FA) and acetic acid (AA) as 70:30 by volume, was added to the prepared biomass in the flask at a fiber to liquor ratio of $1: 8$ and boil on a hot plate for two hours. Thereafter, the flask was let to cool to room temperature. The fibers of the biomass were filtered in a Buchner funnel and washed with $80 \%$ formic acid, and then by hot distilled water.

After pulping, FA/AA treated pulps were further de-lignified by treating them with a mixture of PFA/PAA solution in hot water bath at $80{ }^{\circ} \mathrm{C}$ for two hours. The PFA/PAA mixture solution was prepared by adding $8 \mathrm{ml}$ $35 \% \mathrm{H}_{2} \mathrm{O}_{2}$ with $85 \% \mathrm{FA} / \mathrm{AA}$ mixture. Finally, the delignified fibers were filtered to separate cooking liquor (lignin and hemicellulose mixed with formic acid) from cellulose and washed with hot water. The de-lignified fibers were then subjected to bleaching with $14 \mathrm{ml} 35 \%$ $\mathrm{H}_{2} \mathrm{O}_{2}$ solution $(\mathrm{pH} 11-12)$ in a hot water bath at $8^{\circ} \mathrm{C}$ for two hours. Finally, the pulp was washed with distilled water to remove residual lignin. This process was repeated several times to remove lignin completely. Lignin was isolated by following the procedure suggested by Nuruddin, et al. [19]. The consumed liquor was heated at $105^{\circ} \mathrm{C}$ after pulping and delignification. The lignin dissolved in formic acid was precipitated by adding distilled water ( 5 times more than volume of concentrated liquor), and the precipitate was filtered in a Buchner funnel. Finally, the precipitated lignin was washed with distilled water and vacuum dried over $\mathrm{P}_{2} \mathrm{O}_{5}$.

\subsubsection{Determination of lignin}

Weigh an empty conical flask, and then cancel its weight. Weigh one gram of fine fibers of sugarcane bagasse, and put it in the flask, and then drop wise about $15 \mathrm{ml}$ of $72 \% \mathrm{H}_{2} \mathrm{SO}_{4}$ drop by drop with stirring. Let the beaker till the next day, add $562 \mathrm{ml}$ distilled water, and then reflux for 4 hours after boiling. Filter and wash with hot water several times. The filter paper must be weighed and kept one day in an oven before filtration. Weigh the filter paper with the filtrate of lignin cake. Put the filter paper with the filtrate in a crucible and weigh, then place it in a muffle to eliminate and get rid of the cake and then weigh. The remaining weight is lignin which could be determined as from the following relation:-

$$
\text { Lignin, } \%=\frac{\text { Weight of lignin }- \text { Weight of cake }}{\text { Moisture free pulp }} \times 100
$$

\subsubsection{Carboxy-methylation of lignin}

The formed lignin (LG) from any of the two previous methods was carboxy-methylated by mixing $L G$ with solid $\mathrm{NaOH}$ and $500 \mathrm{ml}$ deionized water at $71^{\circ} \mathrm{C}$ for 30 minutes in a water bath. Thereafter, $37.5 \%$ monochloro-acetic acid (MCAA) solution was drop wised to the mixture for another 30 minutes. This mixture was left for 90 minutes to allow the reactions to take place. Hence, the hydrochloric acid was added step by step to a $10.5 \mathrm{pH}$ solution till reach a neutral. Vacuum filtration separated the carboxy-methylated LG, which was subsequently washed with ethanol several times, and then dried for one day at $70^{\circ} \mathrm{C}$. The prepared carboxymethylated LG was ground with cement powder for 30 minutes till pass through 80 mesh sieves, giving a particle size of $\leq 0.177 \mathrm{~mm}$ to explore its effect on the specific properties and microstructure of the OPC cement pastes $[14,18,19,21]$.

\subsection{Preparation and Methods}

During mixing process, small percentages of the prepared caboxy-methylated lignin (CML) like 0.0, 0.10, $0.15,0.20,0.25,0.30,0.35,0.40 \%$ having the symbols $L 0, L 1, L 2, L 3, L 4, L 5, L 6$ and L7, respectively were first dissolved in the mixing water before its pouring to the cement powder. An electrostatic dispersion occurs to generate a steric hindrance which stabilizes the cement particles capacity to separate and disperse. The OPC powder of was first mixed with water to produce cement pastes and then moulded into one inch cubic stainless steel moulds $\left(2.5 \times 2.5 \times 2.5 \mathrm{~cm}^{3}\right)$, vibrated manually for 
two minutes, and on a mechanical vibrator for another two minutes. The surfaces of pastes inside moulds were smoothed with a suitable trowel or spatula and let to be kept inside a humidity cabinet for $24 \mathrm{hrs}$ at $23 \pm 1^{\circ} \mathrm{C}$ and $100 \%$ relative humidity. In the following day, it demoulded and soon cured under water till the time of testing for bulk density, apparent porosity and compressive strength after 1, 3, 7, 28 and 90 days.

The standard water of consistency [22] and setting times [23] of the various cement pastes were directly measured using Vicat Apparatus (Figure. 4) The water of consistency could be calculated from the following relation:

$$
\text { WC, } \%=A / C \times 100
$$

Where, $A$ is the amount of water taken to produce a suitable paste, $\mathrm{C}$ is the amount of cement mix $(300 \mathrm{~g})$. The initial setting time (IST) is the time taken to reach the initial set, while the final setting time (FST) is the time taken to reach the final set of the paste.

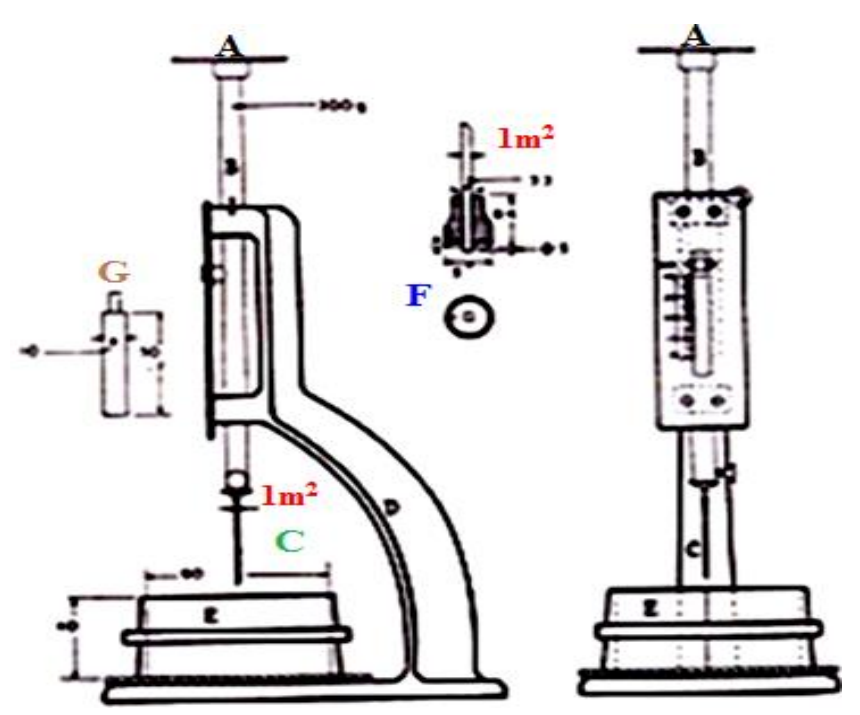

Figure 4 Vicat Apparatus for determining water of consistency and setting times

During mixing, the correct predetermined $\mathrm{w} / \mathrm{c}$ ratio or water of consistency was poured into the cement portion inside the mixer step by step, and then the mixer was run for 5 minutes at an average speed of $10 \mathrm{rpm}$ in order to have perfect homogenous pastes. Before casting of cement cubes, the moulds were washed with a thin film of a motor engine oil to facilitate the release of the cement cubes from the moulds during the demoulding process. The cement pastes were then moulded into one inch cubic stainless steel moulds (2.5 $\times 2.5 \times 2.5 \mathrm{~cm}^{3}$ ) using about 500 grams of the cement powder batch, vibrated manually for three minutes, and then on a mechanical vibrator for another three minutes to remove all air bubbles tapped inside the cement pastes. The moulds were filled to the top surface and smoothed with a flat stainless steel trowel or a suitable spatula to obtain a flat and smooth surface. After casting of samples, they were covered with a wet sheet during the first 24 hours to prevent moisture loss. The moulds were then kept in a humidity chamber for 24 hours under $95 \pm 1$ relative humidity $(\mathrm{RH})$, and room temperature $(23 \pm 1)$, demoulded in the next day, and soon cured by the total immersion in water at an ambient laboratory temperature till the time of testing for heat of hydration, bulk density, total porosity, compressive strength, combined water and free lime contents at $1,3,7,28$ and 90 days $[6,7,23-28]$. This is necessary for the cement cubes as it facilitates the proper hydration of the various cement phases. At the beginning, the curing water was renewed every day for the first 10 days, and then every week. The bulk density (BD) of the hardened cement pastes $[6,7,23-28]$ was calculated from the following equation: -

$$
\text { B.D, }\left(\mathrm{g} / \mathrm{cm}^{3}\right)=\mathrm{W} 1 /(\mathrm{W} 1-\mathrm{W} 2) \times 1
$$

Where, W1, W2 and W3 are the saturated, suspended and dry weights, respectively. The total porosity (TP) of the hardened cement pastes [25-27] was determined from the following relation: -

$$
\text { T.P, \%, } \xi=0.99 \times \text { We } \times \mathrm{dp} /(1+\mathrm{Wt})
$$

Where, T.P. is the total porosity, $\xi, 0.99$ is the specific volume of the free water, We is the evaporable water content, $\mathrm{dp}$ is the bulk density, $\mathrm{g} / \mathrm{cm}^{3}$ and Wt is the total water content which is equal to the sum of evaporable water (We) and combined water (Wn) contents. The compressive strength (CS) of the various hardened cement pastes $[29,30]$ was measured and calculated from the following relation:

$$
\mathrm{CS}=\mathrm{L}(\mathrm{KN}) / \mathrm{Sa} \quad(\mathrm{cm} 2) \quad \mathrm{KN} / \mathrm{m} 2 \quad \mathrm{x} \quad 102
$$

$(\mathrm{Kg} / \mathrm{cm} 2) / 10.2(\mathrm{MPa})$

Where, $L$ is the load taken, Sa is the surface area. Thereafter, about 10 grams of the broken specimens from the determination of compressive strength were first well ground dried at $105^{\circ} \mathrm{C}$ for 30 minutes, and then were placed in a solution mixture of 1:1 methanol: acetone mixture so as to stop the hydration $[6,7,23-26,31,32]$. The kinetics of hydration in terms of chemically bound water and free lime contents were also measured. About one gram of the sample was first dried at $105^{\circ} \mathrm{C}$ for 24 hours and then placed inside a furnace and let to fired up to $1000^{\circ} \mathrm{C}$ for 30 minutes soaking. The chemically-combined water content $(\mathrm{CWn})$ at each hydration age was determined $(31,32)$ from the following equation:

$$
\mathrm{CWn}, \%=\mathrm{W} 1-\mathrm{W} 2 / \mathrm{W} 2 \times 100
$$


Where, CWn, W1 and W2 are combined water content, weight of sample before and after firing, respectively. The free lime content (FLn) of the hydrated samples pre-dried at $105^{\circ} \mathrm{C}$ for 24 hours was also determined. About $0.5 \mathrm{~g}$ sample $+40 \mathrm{ml}$ ethylene glycol $\rightarrow$ heating to about 20 minutes without boiling. About 1-2 drops of $\mathrm{pH}$ indicator were added to the filtrate and then titrated against freshly prepared $0.1 \mathrm{~N} \mathrm{HCl}$ until the pink colour disappeared. The $0.1 \mathrm{~N} \mathrm{HCl}$ was prepared using the following equation:

$\mathrm{V} 1=\mathrm{N} \times \mathrm{V} 2 \times \mathrm{W} \times 100 / \mathrm{D} \times \mathrm{P} \times 1000$

Where, $\mathrm{V} 1$ is the volume of $\mathrm{HCl}$ concentration, $\mathrm{V} 2$ is the volume required, $\mathrm{N}$ is the normality required, $\mathrm{W}$ is the equivalent weight, $\mathrm{D}$ is the density of $\mathrm{HCl}$ concentration and $\mathrm{P}$ is the purity (\%). The heating and titration were repeated several times till the pink color disappeared completely on heating. Then, the free lime content $[23-28,31,32]$ was calculated from the following relation:

$$
\text { FLn, \% }=(\mathrm{V} \times 0.0033 / 1) \times 100
$$

Where, FLn and $V$ are the free lime content, \% and the volume of $0.1 \mathrm{~N} \mathrm{HCl}$ taken on titration, respectively.

The obtained results were then confirmed by Fourier Transform Infrared Spectroscopy (FTIR) and Scanning Electron Microscopy (SEM). The FT-IR spectra were done by Perkin Elmer FT-IR spectrometer in the range of $4000-500 \mathrm{~cm}^{-1}$ and a resolution of $500 \mathrm{~cm}^{-1}$. The SEM microscopy was conducted for some selected samples by using JEOL-JXA-840 electron analyzer at accelerating voltage of $30 \mathrm{KV}$. The fractured surfaces were fixed on Cu-ka stubs by carbon paste and then coated with a thin layer of gold. The SEM images are supported with EDAX analysis.

\section{Results and Discussion}

\subsection{Water of consistency and setting time}

Figureure 5 shows the water of consistency and setting times of the various cement/lignin batches. As it is clear, the water of consistency decreased slightly and continuously with the gradual addition of the lignin admixture. This proved that the lignin admixture acted as a plasticizer [13-16].

On the other side, the setting times, both initial and final, also displayed the same trend as water of consistency $[30,31]$. Consequently, not only the lignin admixture behaves as a plasticizer, but also as an accelerator.

\subsection{Heat of hydration}

The heat of hydration of the various cement/lignin batches hydrated up to 90 days is plotted as a function of cement batches in Figure. 6 .

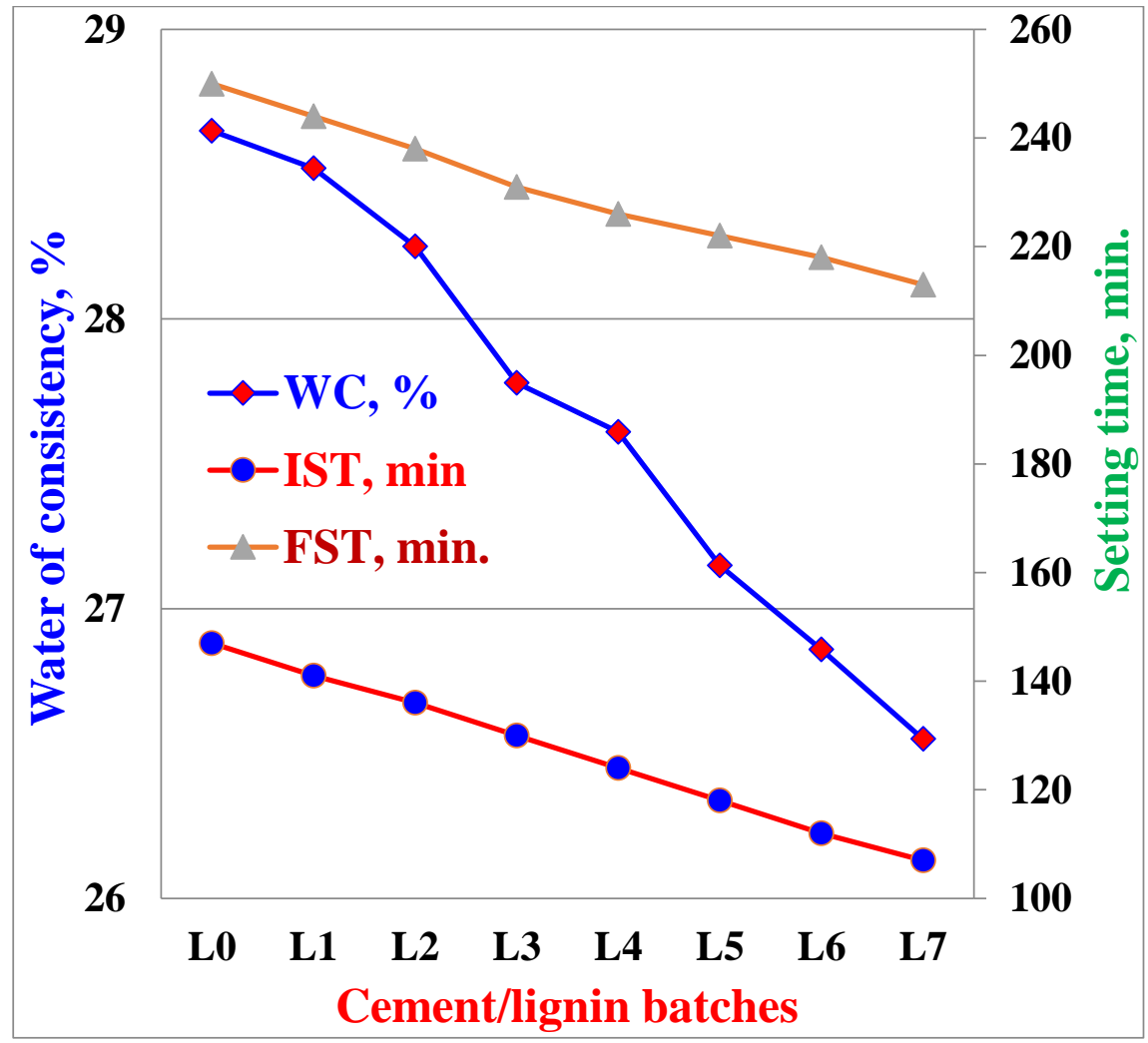

Figure 5 Water of consistency and setting times of cement/ lignin batches. 


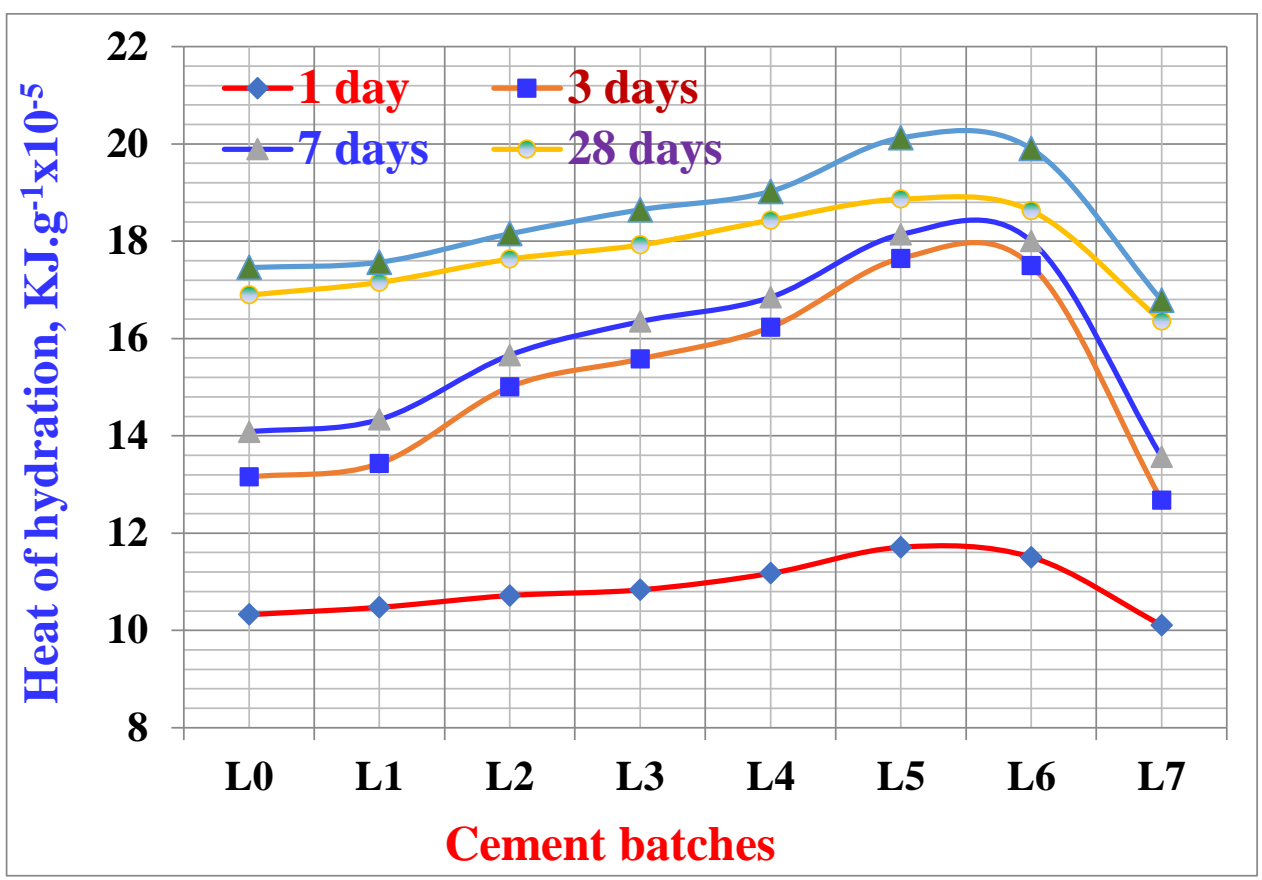

Figure 6 Heat of hydration of cement/lignin batches hydrated up to 90 days.

As it is shown from the Figureure, the heat of hydration increased with the increase of lignin content only up to L5 containing $0.3 \%$ lignin admixture, and then suddenly decreased with further increase of lignin content. This means that the addition of lignin admixture more than $0.3 \%$, the heat of hydration was adversely affected $[14,15,20]$. Therefore, the larger amount of lignin admixture $(>0.3 \%)$ is undesired because it was negatively reflected on the normal hydration process of the cement pastes.

\subsection{Combined water contents}

Figureure 7 demonstrates the relationship between the combined water contents of the various cement/lignin batches hydrated up to 90 days versus cement batches. The combined water contents are continuously increased with hydration ages up to 90 days. Also, the combined water contents increased little by little with the increase of lignin content in the mixture at all hydration ages up to 90 days. This could be achieved till only mixture L 5 containing $0.3 \%$ lignin, but then decreased with further increase of lignin (L6 and L7). This was displayed by all cement batches al all hydration times. The increase of combined water content is mainly attributed firstly to the normal hydration process of cement phases. In addition, the activation response of lignin which aids to improve the hydration process of cement phases. Moreover, the good dispersion and the good compaction caused by lignin during casting that is helping to facilitate more hydration to occur $[6,7,26,32-37]$. The sudden decrease of combined water content with cement batches containing $>0.3 \%$ lignin ( $L 6$ and L7) may be due to that the higher quantity of lignin delays the hydration of cement phases to some extent [30,31,34-36]. Accordingly, the higher amounts of lignin admixture must be avoided although it was stll better and higher than that of the blank (LO), and therefore the optimum ratio of lignin is $0.3 \%(L 5)$.

\subsection{Free $\mathrm{Ca}(\mathrm{OH})_{2}$ content}

The free lime contents, $\mathrm{Ca}(\mathrm{OH})_{2}$ of the various cement/lignin batches hydrated up to 90 days is graphically illustrated as a function of cement batches in Figure. 8. It is obvious that the free lime contents are continuously increased with curing or hydration times up to 90 days [31,32]. The increase of free lime contents is essentially contributed to the normal hydration of calcium silicate phases of the cement $C_{3} S$ and $\beta-C_{2} S$ as follows:

$$
\begin{aligned}
& 3 \mathrm{C}_{3} \mathrm{~S}+6 \mathrm{H}_{2} \mathrm{O} \rightarrow \mathrm{C}_{3} \mathrm{~S}_{2} \mathrm{H}_{3}+3 \mathrm{Ca}(\mathrm{OH})_{2} \\
& 2 \mathrm{~B}-\mathrm{C}_{2} \mathrm{~S}+4 \mathrm{H}_{2} \mathrm{O} \rightarrow \mathrm{C}_{3} \mathrm{~S}_{2} \mathrm{H}_{3}+\mathrm{Ca}(\mathrm{OH})_{2}
\end{aligned}
$$

On the other hand, the free lime contents slightly increased little by little with the increase of lignin ratio in the cement at all hydration ages only with up to $0.3 \%$ lignin, but then decreased with further increase of lignin. The increase of free lime content is principally according to the gradual activation influence of the main cement hydrating material [34-36], while the decrease 
of the free lime content is attributed to the fact that the higher amounts of lignin admixture reduces the workability of the cement pastes, and moreover it represents as an obstacle to cement particles making it to be apart from each other and prevent then to hydrate normally [31,32]. As a result, the quantity of lignin admixture must be limited to be the optimum ratio of equal to $0.3 \%$.

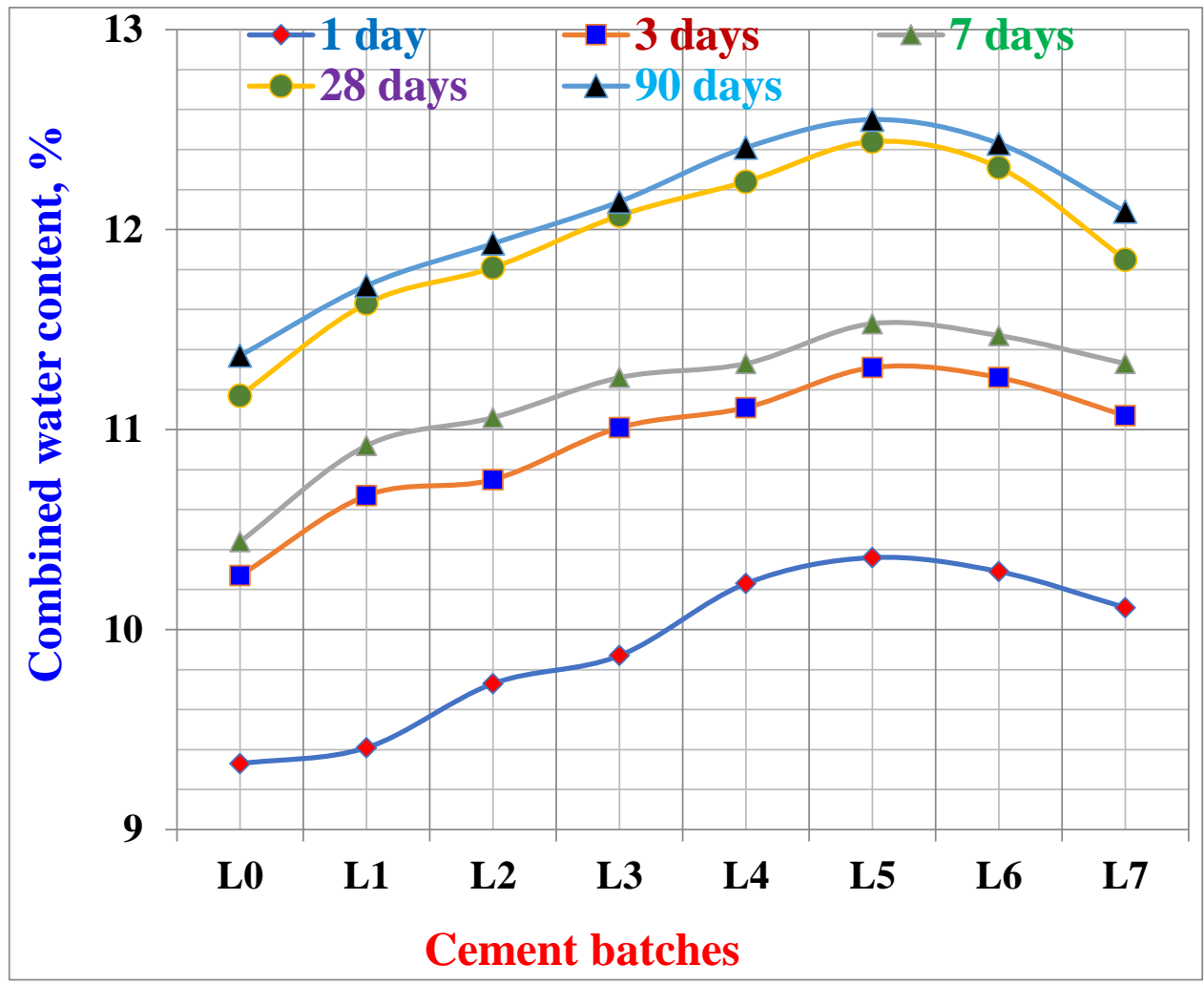

Figure 7 Combined water contents of cement/lignin batches hydrated up to 90 days.

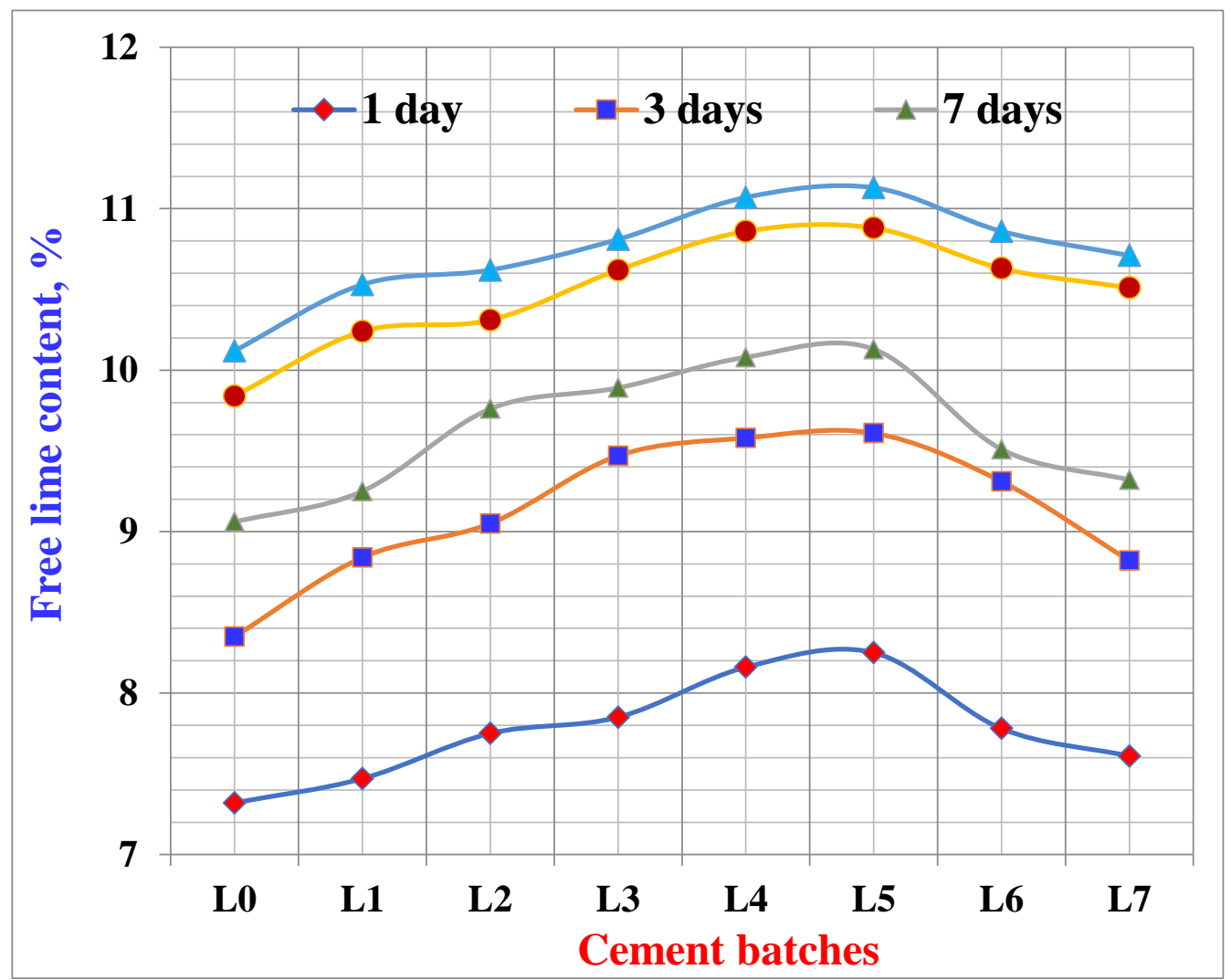

Figure 8 Free lime contents of cement/lignin batches hydrated up to 90 days. 


\subsection{Bulk density and total porosity}

The bulk density and total porosity of the different cement/lignin batches hydrated up to 90 days are graphically represented as a function of cement batches in Figures. 9 and 10, respectively. In a general sense, the bulk density of the different cement batches was improved and increased as the hydration ages progressed up to 90 days, and also as the lignin content increased only up to L5 containing $0.3 \%$ lignin, while the total porosity decreased. With any further increase of lignin content, the bulk density decreased, whereas the total porosity increased.

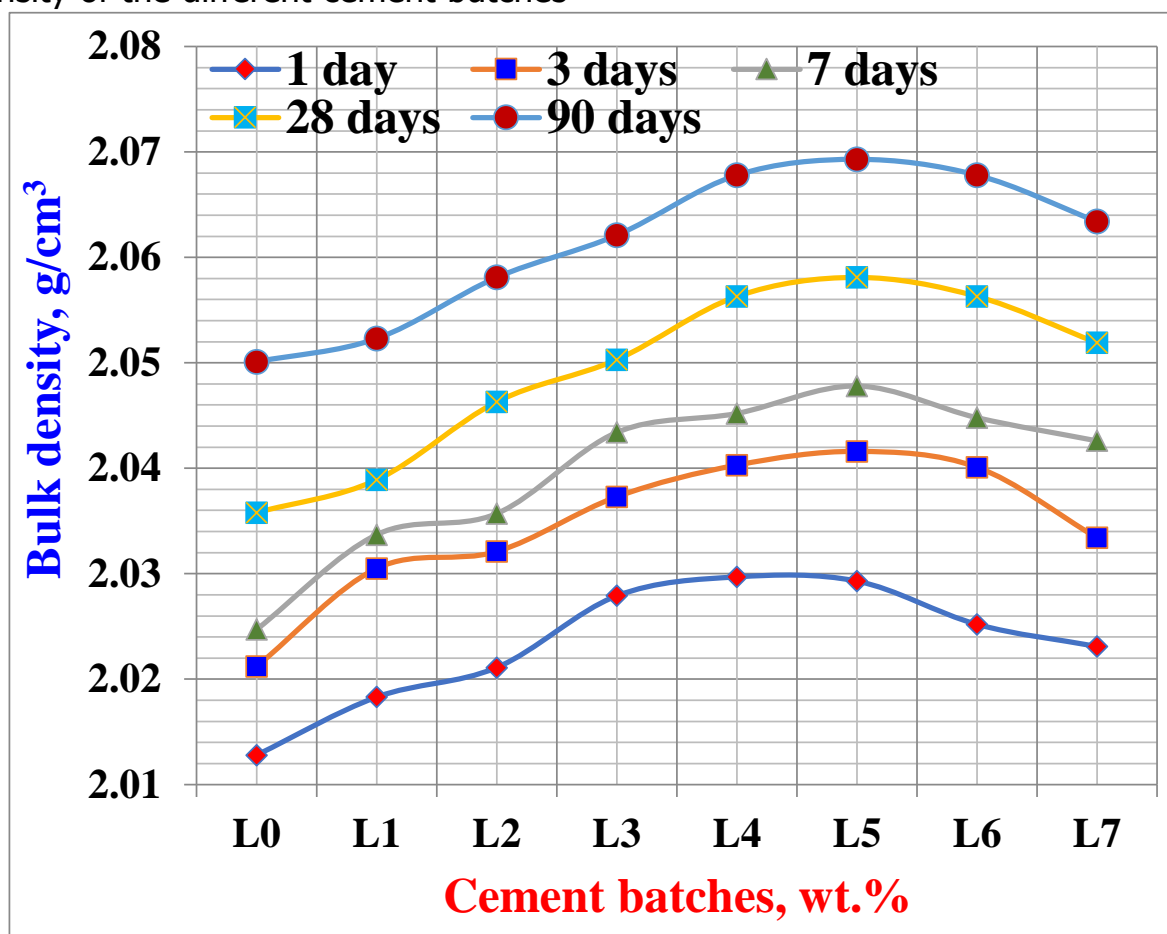

Figure 9 Bulk density of cement/lignin batches hydrated up to 90 days.

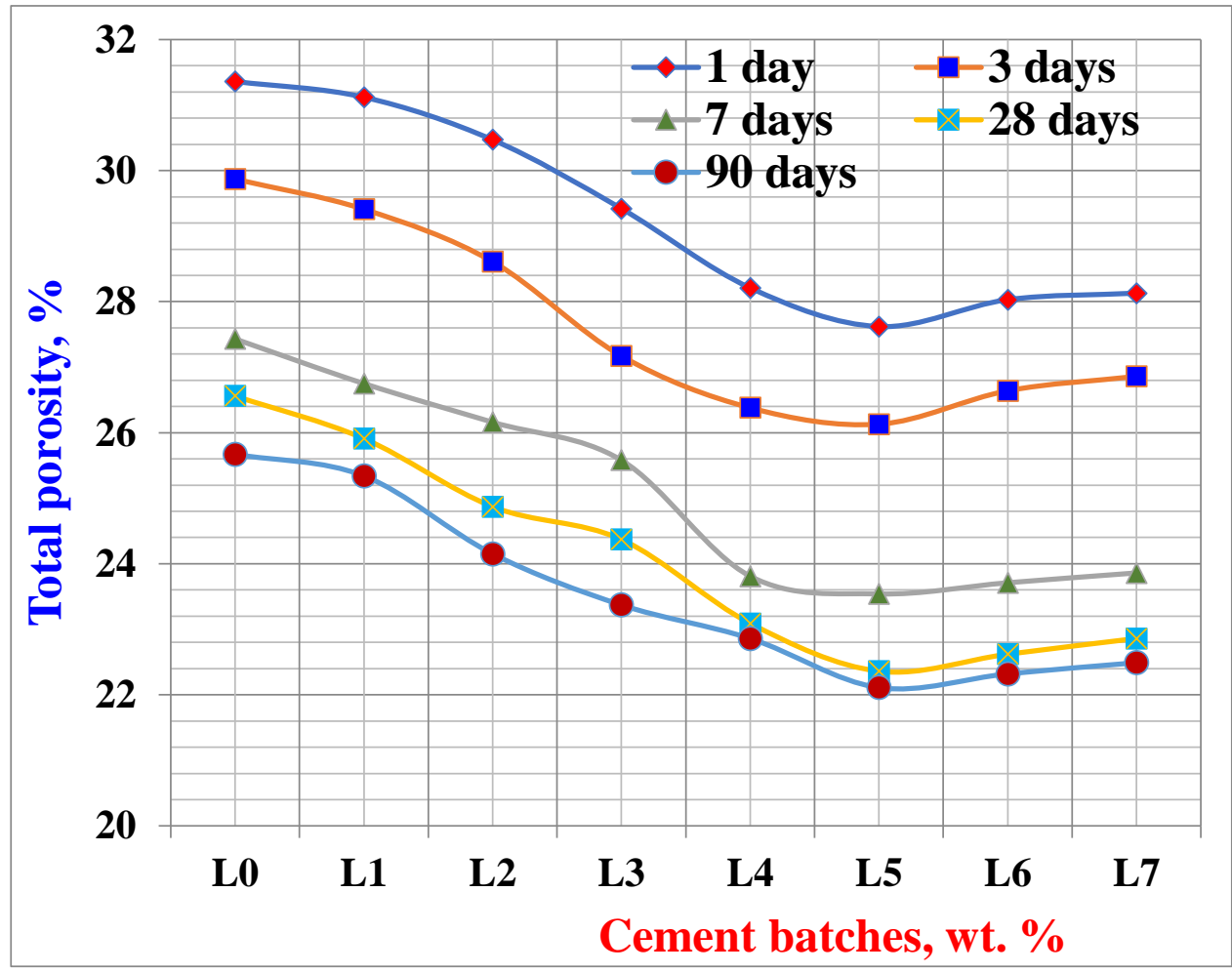

Figure 10 Total porosity of cement/lignin batches hydrated up to 90 days. 
The increase of bulk density and the decrease of total porosity are due to many reasons as the normal hydration of cement phases [31,32], the activation response of lignin to cement phases $[7,9,14,38]$, the filling effect of lignin $[9,14,39]$, and moreover the dispersive influence of lignin and the improving of workability of the cement pastes $[20,28,34,36,40]$. The decrease of bulk density and the increase of total porosity are due to the decrease of the rate of hydration resulting from the higher increase of lignin content, which are often standing as an obstacle that hindered the rate of the normal hydration because this makes for the cement particles to be apart from each other, and therefore the rate of hydration is adversely affected [4143]. Accordingly, the optimum content of lignin admixture to obtain the best results is $0.3 \%$ (L5). The higher ratios of lignin ( $L 6$ and L7) could be avoided though it was still better and higher than those of the blank (LO).

\subsection{Compressive strength}

The compressive strength of the different cement/lignin batches hydrated up to 90 days is plotted as a function of cement batches in Figure. 11. Generally, the compressive strength of the different cement/lignin batches (LO-L7) gradually and continuously increased as the hydration times progressed up to 90 days. This is mainly attributed to the normal hydration process of the major cement phases when being in contact with water
$[31,32,38,39]$. The compressive strength also increased with cement/lignin content, i.e. as the lignin content increased in the cement mix, the compressive strength increased too. This occurred only with up to $0.3 \%$ lignin (L5), and then decreased with more addition of lignin (L6 and L7.

The increase of compressive strength is essentially contributed to several reasons as the hydration of cement phases, especially $C_{3} S, \beta-C_{2} C_{1} C_{3} A$ and $C_{4} A F[9,14,38,41]$, which is the main factor to increase the compressive strength. In addition, the activation effect of lignin to cement phases $[20,39]$ and the filling action of lignin, which sharply decreased the porosity and increased the bulk density $[28,34,36,38,42]$. Furthermore, the dispersive ability of lignin which improves the workability of the cement pastes $[34,36,39,40,43]$. The decrease of compressive strength is firstly due to the decrease of hydration rate as a result of the reduction of workability resulting from the higher dosage of lignin. This means that the higher amounts of lignin were standing as an obstacle that hindered the rate of hydration because this makes for the cement particles to be apart from each other due to it is surrounded by thin films of lignin, and so the rate of hydration is adversely affected [41-43]. As a result, it could be concluded that the optimum content of lignin to obtain the best results is $0.3 \%(\mathrm{~L} 5)$, but the higher quantities of lignin (L6 and L7) could be avoided though it was still better and higher than those of the blank (LO).

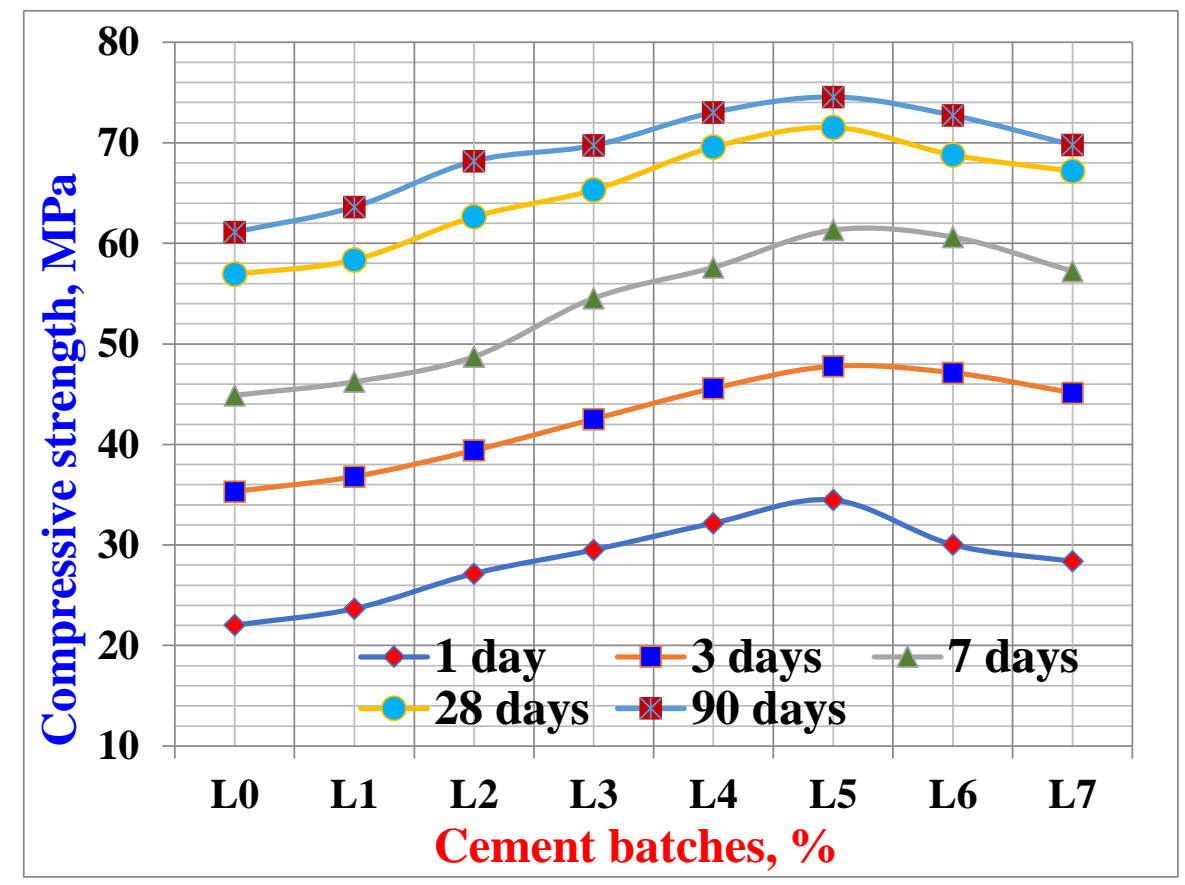

Figure 11 Compressive strength of cement/lignin batches hydrated up to 90 days. 


\subsection{FTIR spectra}

The FTIR spectra of the cement/lignin batches of L0, L3 and L5 hydrated up to 28 days is illustrated in Figure. 12. The sharp absorption band at wave number 3644-3642 $\mathrm{cm}^{-1}$ is related to the free $\mathrm{OH}^{-1}$ group coordinated to $\mathrm{Ca}^{2+}$, i.e. free lime, $\mathrm{Ca}(\mathrm{OH})_{2}$. The intensity of this absorption band of the blank (LO) is clearly detected, which in turn increased slightly with those of L3 and L5. This is mainly attributed to the activation effect of lignin admixture which improves the rate of hydration. The increase of the intensity of free lime proved the increase of hydration. The intensity of the broad absorption band at wave number 3800-3000 $\mathrm{cm}^{-1}$ which is due to the $\mathrm{OH}^{-1}$ group associated to $\mathrm{H}^{+}$ bond, i.e. water, increased with the presence of lignin due to the absorption of large quantity of water molecules to form hydration products. The two absorption bands nearly at $1700-1650$ and $1550-1150$ $\mathrm{cm}^{-1}$ are related to the main silicate band involve Si-O stretching vibration bands of $\mathrm{CSH}$. The intensity of the three absorption bands at $1100-700 \mathrm{~cm}^{-1}$ that are characterizing $\mathrm{CO}_{3}{ }^{2-}$ and $\mathrm{SO}_{4}^{2-}$, increased with lignin content. This may be due to the rate of carbonation and sulfonation of $\mathrm{CSH}$ and /or CAH. The intensity of the absorption band of $\mathrm{CSH}$ was increased with lignin content.

\subsection{SEM-EDAX analysis}

The SEM images of the hydrated interfacial layers of L0, L3 and L5 hydrated up to 90 days supported with EDAX are shown in Figure. 13. It is clear that the blank cement pastes (LO) included CSH, higher ratio of ettringite, $\mathrm{C}_{3} \mathrm{~A} .3 \mathrm{CaSO}_{4} .32 \mathrm{H}_{2} \mathrm{O}$ as a needle-like crystals, thick sheets of gypsum, and white pits of portlandite, $\mathrm{Ca}(\mathrm{OH})_{2}$, i.e. free lime, while those of $\mathrm{L} 3$ and $\mathrm{L} 5$ showed a little ratio of ettringite and/or portlandite, but higher ratio of $\mathrm{CSH}$. There were small amounts of carboaluminate hydrate phases in L3, but thin sheets of carbo-aluminate hydrate phase were detected in L5, i.e. ettringite and gypsum were disappeared in the cement pastes containing $0.3 \%$ lignin (L5).

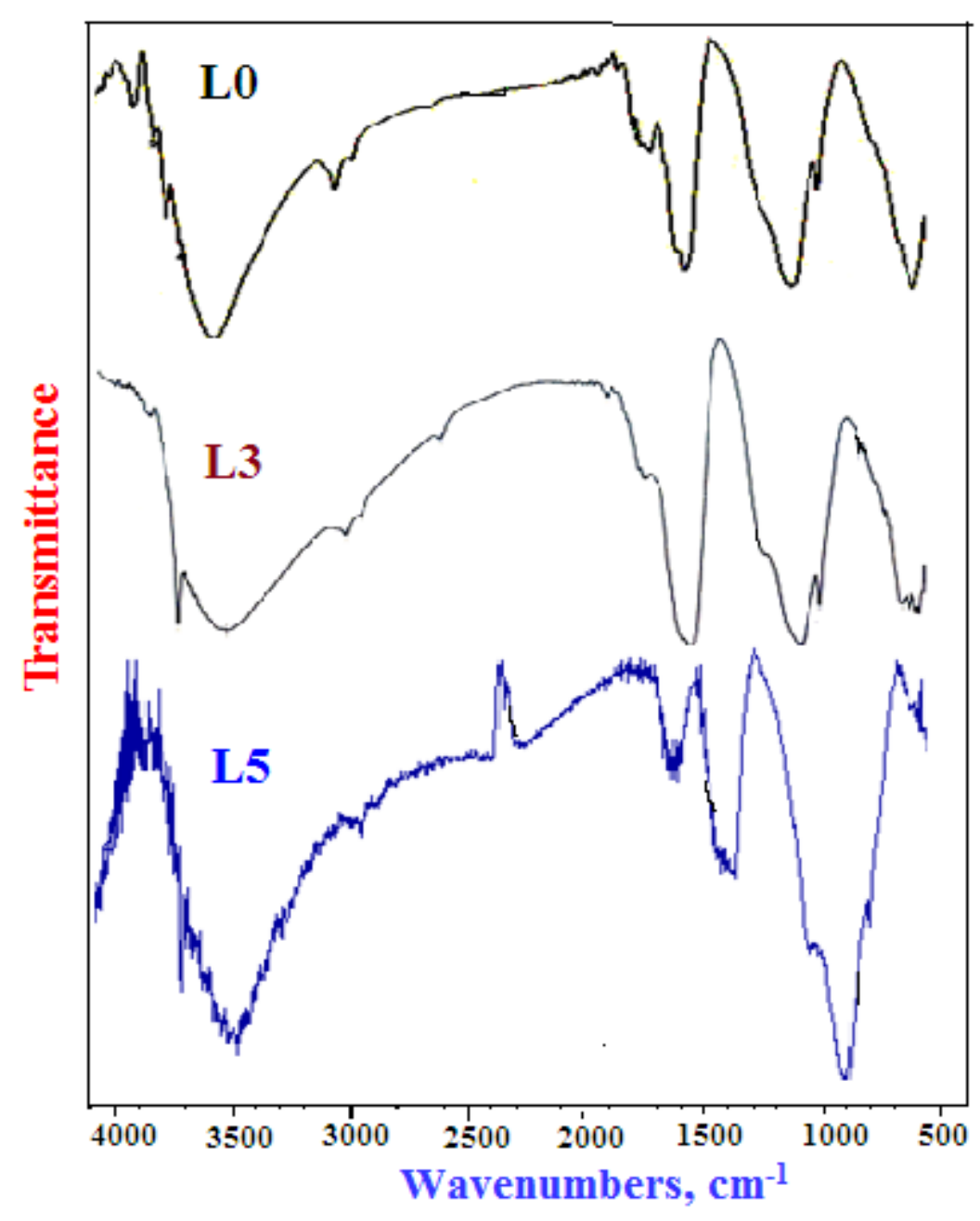

Figure 12 FTIR spectra of the OPC/lignin cement pastes of L0, L3 and L5 hydrated up to 28 days. 


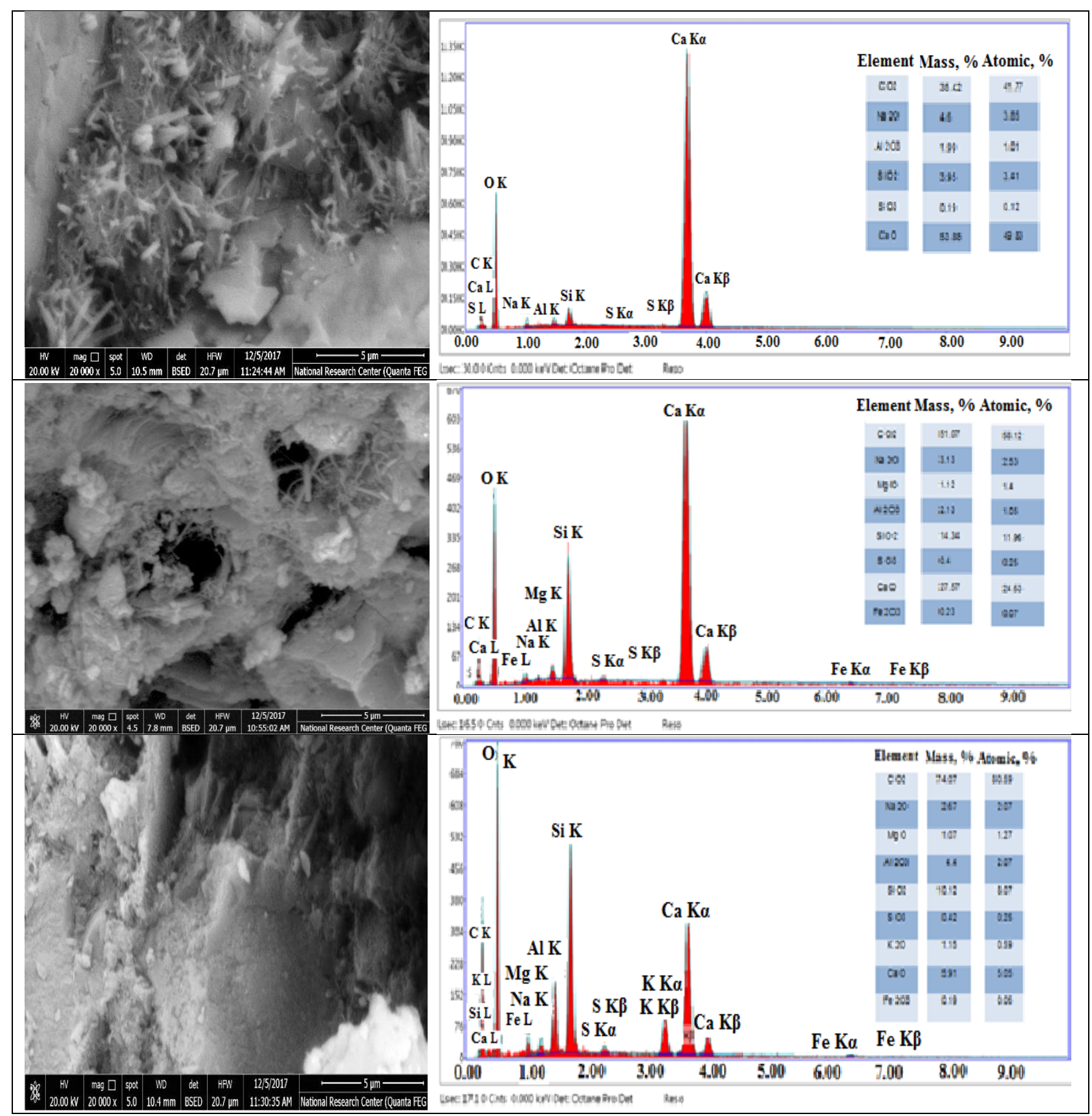

Figure 13 SEM images of the cement/lignin pastes hydrated up to 28 days supported with EDAX analysis.

Furthermore, the quantity of CSH was higher in presence of lignin if compared with those of the blank (LO). This is the main cause for improving of the specific characteristics of cement pastes, particularly compressive strength when compared with those of the blank (LO). From an engineering point of view, the CSH gel formed in presence of the colloidal layers of lignin, water can be absorbed between these layers as crystals and/or xerogel, which can absorb water. The microstructure of the lignin/cement pastes can explain the improvements of physical, chemical and mechanical properties of the cement pastes of L3 and L5. This may be the key to explain the different modifications that occurred in the prepared cements. EDAX analysis showed that in blank ( $\mathrm{LO}), \mathrm{Ca}^{+2}, \mathrm{Al}^{+3}, \mathrm{Fe}^{+3}$, and $\mathrm{SO}_{3}$ were detected. These elements were also detected with $\mathrm{L3}$, $\mathrm{L} 5$ with larger ratios, in addition to $\mathrm{CO}_{3}{ }^{-2}, \mathrm{SiO}_{2}$, and few traces of other elements.

\section{Conclusions}

1- The $w / c$ ratio (water of consistency) and setting times (initial and final) of the blank (L0) were decreased with the increase of lignin content.

2- The heat of hydration, combined water, bulk density and compressive strength of the blank (LO) increased with the increase of lignin content only up to $0.3 \%(L 5)$, and then decreased. 
3- The free lime content of the blank (LO) decreased with the increase of lignin content at all hydration times.

4- The total porosity of the blank (LO) decreased with the lignin content merely up to $0.3 \%(L 5)$, but then increased suddenly.

5-The FTIR spectra showed that the intensity increase of peaks characterizing the free lime at the range of wavenumber $3644-3642 \mathrm{~cm}^{-1}$ proved that the rate of hydration improved and enhanced with the increase of lignin content.

6-The SEM-EDAX image analysis indicated that the microstructure of cement/lignin pastes is better than that of the blank (LO). This is due to the lack of ettringite $\left(\mathrm{C}_{3} \mathrm{~A}, 3 \mathrm{CaSO}_{4} .32 \mathrm{H}_{2} \mathrm{O}\right)$ and portlandite, $\mathrm{Ca}(\mathrm{OH})_{2}$ ratios in the cement pastes, which in turn modified the microstructure of CSH.

\section{References}

[1] C.A.S. Costa, W. Coleman, M, Dube, A.E. Rodrigues, P.C.R. Pinto, Assessment of key features of lignin from lignocellulosic crops: stalks and roots of corn, cotton, sugarcane, and tobacco, Industrial Crops and Products, 92 (2016) 136-148. [DOI]

[2] A.H. Abdel-Kader, H.H.M. Darweesh, Setting and hardening of Agro/cement composites, BioResources, 4 (2010) 43-54.

[3] T.S. Abdulkadir, D.O. Oyejobi, A.A. Lawal, Evaluation of Sugarcane Bagasse Ash as a Replacement for Cement in Concrete Works, Acta Tehnica Corviniensis - Bulletin of Engineering, 7 (2014) 71-76.

[4] M.K. Idris, K. Eldin, E. Yassin, Determination of the effects of bagasse ash on the properties of Portland cement, Journal of Applied and Industrial Sciences, 3 (2015) 6-11.

[5] A.P. Jayminkumar, D.B. Raijiwala, Experimental studies on strength of RC concrete by partially replacing cement with sugarcane bagasse ash, International Journal of Engineering Research \& Technology, 4(2015), 2228-2232.

[6] H.H.M, Darweesh, M.R. Abo El-Suoud, Saw dust ash substitution for cement pastes-Part I, American Journal of Construction and Building Materials, 3 (2017), 63-71

[7] H.H.M. Darweesh, M.R. Abo El-Suoud, Influence of sugarcane bagasse ash substitution on Portland cement characteristics, Indian Journal of Engineering, 16 (2019) 252-266

[8] L. Passauer, K. Salzwedel, M. Struch, N. Herold, J. Appelt, Quantitative analysis of the etherification degree of phenolic hydroxyl groups in oxyethylated lignins: correlation of selective aminolysis with FTIR spectroscopy, ACS Sustainable Chemistry \& Engineering, 4(2016) 6629-6637. [DOI]

[9] H.H.M. Darweesh, M.G. El-Meligy, Pulp White Liquor Waste as a Cement Admixture-Part I, American Journal of Mining and Metallurgy 2 (2014) 88-93.

[10] O.A. Fadele, O. Ata, Water absorption properties of sawdust lignin stabilised compressed laterite bricks. Case Studies in Construction Materials, 9(2018), e00187. [DOI]

[11] A.A. Ibrahim, A.E. Abdel-Megied, M.S. Selim, H.H.M. Darweesh, M.M. Ayoub, New Polymeric Admixture for Cement Based on Hyperbranched Poly Amide-Ester with Pentaerythritol Core Hyperbranched Poly Amide-Ester with Pentaerythritol Core, Hindawi ISRN Materials Science, 2013, 1-7. [DOI]

[12] H.H.M. Darweesh, Utilization of CaLignosulphonate Prepared From Black Liquor Waste as a Cement Superplasticizer, Journal of Chemistry and Materials Research, 1(2014) 2834.

[13] M. Francisco, A. van den Bruinhorst, M.C. Kroon, New natural and renewable low transition temperature mixtures (LTTMs): screening as solvents for lignocellulosic biomass processing. Green Chemistry, 14 (2012) 2153-2157. [DOI]

[14] J.G. Lynam, N. Kumar, M.J. Wong, Deepeutectic solvents' ability to solubilize lignin, cellulose, and hemicellulose; thermal stability; and density. Bioresource Technology 238(2017) 684-689. [DOI]

[15] J. Gorke, F. Srienc, R. Kazlauskas, Toward Advanced Ionic Liquids. Polar, Enzymefriendly Solvents for Biocatalysis, Biotechnology and Bioprocess Engineering, 15(2010) 40-53. [DOI]

[16] L. Hu, H. Pan, Y. Zhou, M. Zhang, Methods to improve lignin's reactivity as a phenol substitute and as replacement for other phenolic compounds: a brief review, BioResources, 6(2011) 3515-3525.

[17] D.-Y. Min, S.W.Smith, H.-M. Chang, H. Jameel, Influence of isolation condition on structure of milled wood lignin characterized by quantitative $13{ }^{\circ} \mathrm{C}$ nuclear magnetic resonance spectroscopy, BioResources, 8(2013) 1790-800.

[18] N. Brosse, M.N.M. Ibrahim, A.A. Rahim, Biomass to bioethanol: initiatives of the future for lignin, International Scholarly Research Notices, (2011) 1-10. [DOI]

[19] S.S. Soni, Lignin in phenol-formaldehyde adhesives, International Journal of Knowledge Engineering, 3(2012) 116-118.

[20] L. Gan, M. Zhou, D. Yang, X. Qiu, Preparation 
and Evaluation of Carboxymethylated Lignin as Dispersant for Aqueous Graphite Suspension Using Turbiscan Lab Analyzer, Journal of Dispersion Science \& Technology 34(2013) 644650. [DOI]

[21] D. Watkins, Md. Nuruddin, M. Hosur, A. TcherbiNarteh, S. Jeelani, Extraction and characterization of lignin from different biomass resources, Journal of Materials Research and Technology, 4(2015) 26-32. [DOI]

[22] ASTM-Standards C187-86 (1993) Standard test method for normal consistency of hydraulic cement, 148-150.

[23] ASTM-Standards, C191-92 (1993) Standard test method for setting time of hydraulic cement by Vicat apparatus, 866-868.

[24] H.H.M. Darweesh, Setting, Hardening and Mechanical Properties of Some Cement / Agrowaste Composites - Part I, American Journal of Mining and Metallurgy, 2(2014) 3240.

[25] HHM. Darweesh, Metakaolin Blended Cement Pasttes, International Journal Innovative Studies in Sciences and Engineering Technology, 6(2020) 5-18.

[26] H.H.M. Darweesh, Characteristics of Portland cement pastes blended with Silica Nanoparticles, To Chemistry, 5(2020) 1-14.

[27] H.H.M. Darweesh, M.R. Abo El Suoud, Effect of Agricultural Waste Material on the Properties of Portland Cement Pastes, Research \& Development in Material science, 13(2020) 1360-1367. [DOI]

[28] H.H.M. Darweesh, Cement Pastes Containing Polypropylene Fibers - Part I: Physical, Chemical and Mechanical Properties, To Chemistry, 6 (2020) 23-34.

[29] ASTM-Standards C170-90 (1993) Standard test method for compressive strength of dimentional strones, 828-830.

[30] ASTM-C109 M (2013) Standard Test Method for Compressive Strength of Hydraulic Cement Mortars (Using 2-in. or $50 \mathrm{~mm}$ Cube Specimens), Annual Book of ASTM-Standards. ASTM-International, West Conshohocken, PA.

[31] Neville AM (2011) Properties of Concrete, $5^{\text {th }}$ Edn, Longman Essex, UK.

[32] P.C. Hewlett, M. Liska, (2017) Lea's Chemistry of Cement and Concrete, $5^{\text {th }}$ ed., Edward Arnold Ltd., London, England

[33] I.B. Topçu, Ö. Ateşin, Effect of high dosage lignosulphonate and naphthalene sulphonate based plasticizer usage on micro concrete properties. Construction and Building Materials,

\section{0(2016) 189-197. [DOI]}

[34] T.U. Mohammed, T. Ahmed, S.M. Apurbo, T.A. Mallick, F. Shahriar, A. Munim, M.A. Awal, Influence of chemical admixtures on fresh and hardened properties of prolonged mixed concrete. Advances in Materials Science and Engineering, (2017) 1-11. [DOI]

[35] H.H.M. Darweesh, Mortar Composites Based on Industrial Wastes, International Journal of Materials Lifetime, 3(2017) 1-8.

[36] N. Sanjeev, K.H. Kumar, K.P. Kumar, Strength and durability.y characteristics of steel fibre reinforced concrete with mineral admixtures, International Journal of Engineering and Advanced Technology, 9 (2019), 3893-3897. [DOI]

[37] A. Amin, H.H.M. Darweesh, A.M. Ramadan, S.M.M. Morsi, M.M.H. Ayoub, Employing of Some Hyperbranched Polyesteramides as New Polymeric Admixtures for Cement, Journal of Applied Polymer Science, 121(2011) 309-320. [DOI]

[38] A. Amin, H.H.M. Darweesh, S.M.M. Morsi, M.M.H. Ayoub, Effect of Phthalic anhydride based Hyper-branched Polyesteramide on Cement Characteristics, Journal of Applied Polymer Science, 120 (2011) 3054-3064. [DOI]

[39] A. Amin, H.H.M. Darweesh, A.M. Ramadan, S.M.M. Morsi, M.M.H. Ayoub, Modification of Cement with Succinic Anhydride-Based Hyperbranched Polyesteramide, Journal of Applied Polymer Science, 124(2012) 1483-1489. [DOI]

[40] H.H.M. Darweesh, M.R. Abo El-Suoud, Palm Ash as a Pozzolanic Material for Portland Cement Pastes, To Chemistry Journal, 4(2019) 72-85.

[41] Q. Yang, J. Shi, L. Lin, Characterization of structural changes of lignin in the process of cooking of bagasse with solid alkali and active oxygen as a pretreatment for lignin conversion, Energy \& Fuels, 26(2012) 6999-7004. [DOI]

[42] Q.Wang, S. Liu, G. Yang, J. Chen, Characterization of high-boiling-solvent lignin from hot-water extracted bagasse, Energy \& Fuels, 28(2014) 3167-3171. [DOI]

[43] B. Jiang, T. Cao, F. Gu, W. Wu, Y. Jin, Comparison of the structural characteristics of cellulolytic enzyme lignin preparations isolated from wheat straw stem and leaf, ACS Sustainable Chemistry \& Engineering, 5(2017) 342-349, 2017. [DOI] 


\section{Acknowledgement}

The author wishes to express their deep thanks to National Research Centre for helping to obtain materials, processing, preparing, molding and measuring all of the obtained data of the study, and moreover for financial assistance.

\section{Funding}

No funding was received for conducting this study.

\section{Does this article screened for similarity?}

Yes

\section{Conflict of interest}

The Author has no conflicts of interest to declare that they are relevant to the content of this article.

\section{About the License}

(C) The author(s) 2021. The text of this article is open access and licensed under a Creative Commons Attribution 4.0 International License 